\title{
Modal Parameters Estimation of Building Structures from Vibration Test Data Using Observability Measurement
}

\author{
Jae-Seung Hwang, ${ }^{1}$ Hongjin Kim, ${ }^{2}$ and Bong-Ho Cho ${ }^{3}$ \\ ${ }^{1}$ School of Architecture, Chonnam National University, Gwangju 500-757, Republic of Korea \\ ${ }^{2}$ School of Architecture \& Civil Engineering, Kyungpook National University, Daegu 702-701, Republic of Korea \\ ${ }^{3}$ School of Architecture, Ajou University, Gyeonggi-do 443-749, Republic of Korea \\ Correspondence should be addressed to Hongjin Kim; hjk@knu.ac.kr
}

Received 13 October 2014; Revised 21 January 2015; Accepted 26 January 2015

Academic Editor: Roger Serra

Copyright (C) 2015 Jae-Seung Hwang et al. This is an open access article distributed under the Creative Commons Attribution License, which permits unrestricted use, distribution, and reproduction in any medium, provided the original work is properly cited.

\begin{abstract}
The load distribution to each mode of a structure under seismic loading depends on the modal participation factors and mode shapes and thus the exact estimation of modal participation factors and mode shapes is essential to analyze the seismic response of a structure. In this study, an identification procedure for modal participation factors and mode shapes from a vibration test is proposed. The modal participation factors and mode shapes are obtained from the relationship between observability matrices realized from the system identification. Using the observability matrices, it is possible to transform an arbitrarily identified state space model obtained from the experimental data into a state space model which is defined in a domain with physical meaning. Then, the modal participation factor can be estimated based on the transformation matrix between two state space models. The numerical simulation is performed to evaluate the proposed procedure, and the results show that the modal participation factor and mode shapes are estimated from the structural responses accurately. The procedure is also applied to the experimental data obtained from the shaking table test of a three-story shear building model.
\end{abstract}

\section{Introduction}

The modal participation factors and mode shapes are coefficients that represent how the ground acceleration is distributed to each mode of a building structure. This is because the inertial force, which is generated by the ground acceleration and the mass of each floor, is distributed to each mode through the modal participation factor for typical building structure. Ground vibrations can be affected by natural processes like earthquakes as well as by human events such as transportation [1], civil work [2], blasting [3], and industrial activities. For this reason, the method to calculate the modal participation factor and mode shape is presented in many references in the area of dynamics of building structures $[4,5]$.

Kim and Choi [6] presented a nonlinear static analysis procedure for the design of supplementary dampers that uses the modal participation factor of the fundamental mode to obtain base shear versus roof-story displacement capacity curve of a structure from pushover analysis. Park et al. [7] proposed a factored modal combination method for accurate prediction of the inelastic earthquake response of a structure by pushover analysis. The modal combination factors for each mode in their proposed method are calculated based on the modal participation factor. Reinoso and Miranda [8] presented a method to estimate lateral acceleration demands in high-rise buildings. The acceleration demands are obtained by approximating the dynamic behavior of the building with that of a continuous beam which is characterized by mode shapes, period ratios, and modal participation factors. Bracci [9] presented a simplified procedure for evaluating the seismic performance and retrofit of existing low to midrise reinforced concrete buildings whose story demands are estimated using the modal participation factor and mode shape.

The modal participation factors and mode shapes of an idealized analytical model, however, are different from the actual one due to modeling and construction error. Therefore, there exist limits on the estimation of actual behavior. Due 
to the discrepancies between an idealized shear building model and a real structure, the modal participation factors and mode shapes may be calculated with errors resulting in incorrect estimation of structural behavior. Zhou et al. [10] reported that the excitation on the time-varying structures is unknown and random in many real-life applications so that output-only methods are appropriate.

Research on the identification of the dynamic parameters of a structure such as natural frequency and damping ratio using the output-only methods has been widely performed utilizing the system identification theory [11-13]. System identification in time and frequency domains have been studied actively $[14,15]$ and the identification of linear system as well as nonlinear system has been studied in various fields of engineering [16-18]. Cho et al. [19] and Kang et al. [20] extended the application of the output-only method to the identification of the secondary mass dampers such as tuned mass dampers and tuned liquid dampers installed on tall buildings to suppress wind-induced motion.

In order to estimate the modal participation factor from a vibration test, it is required to know the mass matrix and mode shape by the definition. That is, the more reliable modal participation factors can be obtained if sensors are installed on every floor so that the mode shape is measurable. However, it is not feasible to measure the dynamic behaviors of every floor in practice due to installation problem and laborious data processing procedure. Meanwhile, in the case of the estimation of damping ratio and modal frequencies that are defined by mass, stiffness, and damping matrices, the damping and frequency values for each mode can be directly estimated from the test without calculating those matrices [14]. Likewise, if the modal participation factor can be obtained directly from the test, not indirectly from the estimated mass matrix and mode shape, the dynamic characteristics and actual behavior of structures can be more precisely understood and modal participation factors can be more effectively utilized.

In this study, an identification procedure for modal participation factors and mode shapes directly from the measured response is proposed. The modal participation factors and mode shapes are obtained from the relationship between observability matrices realized from the system identification. Because the observability matrices can be easily constructed without knowledge of mass, stiffness, and damping matrices of the structure, it is possible to identify the modal participation factor directly from the measured response using the proposed method.

For the numerical derivation to estimate the modal participation factor, the single-input single-output (SISO) system in continuous time domain is considered. Accordingly, the proposed procedure has an advantage that the modal participation factor of the modes that are normalized to a certain element can be estimated from the response of the corresponding floor without knowing responses of other floors. That is, the proposed method can be utilized for the estimation of modal participation factor even when the sensors are not installed on every floor and thereby the mode shape is not available. Further, the mode shapes can also be estimated directly from the experimentally estimated modal participation factors. The numerical simulation is performed to evaluate the proposed procedure, and the procedure is also applied to the experimental data obtained from the shaking table test of a three-story shear building model.

\section{Modal Parameters Estimation}

2.1. Modal Participation Factor. The equation of motion for an $n$-story shear building subjected to earthquake is

$$
\mathbf{M} \ddot{\mathbf{x}}+\mathbf{C} \dot{\mathbf{x}}+\mathbf{K x}=-\mathbf{M}\{1\} \ddot{x}_{g}
$$

where $\mathbf{M}, \mathbf{C}$, and $\mathbf{K}$ are mass, damping, and stiffness matrices of the structure, respectively, $\{1\}$ is an $n \times 1$ column vector with all elements equal to one, $\mathbf{x}$ is an $n \times 1$ column vector of the relative displacement of the structure to ground, and $\ddot{x}_{g}$ is ground acceleration. Equation (1) can be expressed in the modal coordinate system as (3) using the transformation expressed in (2)

$$
\begin{gathered}
\mathbf{x}=\boldsymbol{\Phi} \boldsymbol{\eta}, \\
\boldsymbol{\Phi}^{T} \mathbf{M} \boldsymbol{\Phi} \ddot{\eta}+\boldsymbol{\Phi}^{T} \mathbf{C} \boldsymbol{\Phi} \dot{\eta}+\boldsymbol{\Phi}^{T} \mathbf{K} \boldsymbol{\Phi} \boldsymbol{\eta}=-\boldsymbol{\Phi}^{T} \mathbf{M}\{1\} \ddot{x}_{g},
\end{gathered}
$$

where $\boldsymbol{\eta}$ is the generalized modal coordinate and $\boldsymbol{\Phi}$ is the mode shape matrix. Using the normal coordinate transformation, the equation of the $i$ th mode is given by

$$
\ddot{\eta}_{i}+2 \xi_{i} \omega_{i} \dot{\eta}_{i}+\omega_{i}^{2} \eta_{i}=-\frac{\phi_{i}^{T} \mathbf{M}\{1\}}{\boldsymbol{\phi}_{i}^{T} \mathbf{M} \phi_{i}} \ddot{x}_{g}
$$

where $\phi_{i}$ is the mode shape, $\eta_{i}$ is the modal displacement, $\xi_{i}$ is the modal damping ratio and $\omega_{i}$ is the frequency of the $i$ th mode. The modal participation factor of the $i$ th mode, $\Gamma_{i}$, is defined from (4) by [4]

$$
\Gamma_{i}=\frac{\phi_{i}^{T} \mathbf{M}\{1\}}{\boldsymbol{\phi}_{i}^{T} \mathbf{M} \boldsymbol{\phi}_{i}} .
$$

It is apparent from (5) that the modal participation factor is not a unique value but varies depending on the normalization method of mode shapes as well as floor mass distribution.

2.2. Modal Participation Factor Estimation Using System Identification. For a SISO system with an acceleration output, the output for $p$ th floor is obtained from (2) as

$$
\ddot{x}_{p}=\left[\begin{array}{llll}
\phi_{p 1} & \phi_{p 2} & \cdots & \phi_{p n}
\end{array}\right]\left[\begin{array}{c}
\ddot{\eta}_{1} \\
\ddot{\eta}_{2} \\
\vdots \\
\ddot{\eta}_{n}
\end{array}\right] \text {, }
$$


where $\phi_{p i}$ is the $p$ th element of the $i$ th mode shape. If the $p$ th element of each mode is normalized to unit value, (6) becomes

$$
\ddot{x}_{p}=\left(\begin{array}{llll}
1 & 1 & \cdots & 1
\end{array}\right)\left(\begin{array}{c}
\ddot{\eta}_{1} \\
\ddot{\eta}_{2} \\
\vdots \\
\ddot{\eta}_{n}
\end{array}\right) .
$$

The equation of motion presented in (4) and the output for $p$ th floor of (7) can be transformed into the state space form as

$$
\begin{aligned}
& \dot{\mathbf{z}}=\left(\begin{array}{cc}
\mathbf{O}_{n \times n} & \mathbf{I}_{n \times n} \\
\boldsymbol{\Omega} & \boldsymbol{\Lambda}
\end{array}\right) \mathbf{z}+\left(\begin{array}{c}
\mathbf{O}_{n \times 1} \\
-\{\Gamma\}_{p}
\end{array}\right) \ddot{x}_{g}, \\
& y=\left(\begin{array}{lllllll}
\omega_{1}^{2} & \cdots & \omega_{n}^{2} & -2 \xi_{1} \omega_{1} & \cdots & -2 \xi_{n} \omega_{n}
\end{array}\right)\left(\begin{array}{c}
\eta_{1} \\
\vdots \\
\eta_{n} \\
\dot{\eta}_{1} \\
\vdots \\
\dot{\eta}_{n}
\end{array}\right) \\
& +\sum_{i=1}^{n}-\left\{\Gamma_{i}\right\}_{p}
\end{aligned}
$$

where $\mathbf{z}=\left[\begin{array}{ll}\eta_{i} & \dot{\eta}_{i}\end{array}\right]^{T}$ is the state variable, $y$ is the relative acceleration of the $p$ th floor to ground, $\mathbf{O}_{n \times n}$ and $\mathbf{I}_{n \times n}$ are the zero and identity matrices of size $n \times n$, respectively, $\mathbf{O}_{n \times 1}$ is the zero vector of size $n \times 1,\{\Gamma\}_{p}$ is the $n \times 1$ vector consisting of the modal participation factors of modes normalized to the $p$ th element, $\left\{\Gamma_{i}\right\}_{p}$ is the $i$ th element of $\{\Gamma\}_{p}$, and diagonal matrices $\boldsymbol{\Omega}$ and $\boldsymbol{\Lambda}$, respectively, are

$$
\begin{gathered}
\boldsymbol{\Omega}=\operatorname{diag}\left(-\omega_{i}^{2}, i=1, \ldots, n\right), \\
\boldsymbol{\Lambda}=\operatorname{diag}\left(-2 \xi_{i} \omega_{i}, i=1, \ldots, n\right) .
\end{gathered}
$$

Equations (8a) and (8b) can be simplified as

$$
\begin{gathered}
\dot{\mathbf{z}}=\mathbf{A z}+\mathbf{b} u, \\
y=\mathbf{c z}+\mathbf{d} u,
\end{gathered}
$$

where $u$ is the input to the SISO system, that is, the ground acceleration, and $\mathbf{A}, \mathbf{b}, \mathbf{c}$, and $\mathbf{d}$ are $2 n \times 2 n, 2 n \times 1,1 \times 2 n$, and $1 \times 1$ system matrices, respectively.

The state space model presented in (10a) and (10b) has a physical sense because it is derived from (1) which is defined in terms of a second order differential equation whose variable and its derivatives have physical meaning. In this study, the state space model defined in physical domain is denoted as a typical state space model. It is observed from (8a), (8b), $(10 \mathrm{a})$, and (10b) that the modal participation factor for each mode can be estimated if the system matrix $\mathbf{b}$ of the typical state space model is obtained.

The state variable and state space model realized from the vibration test using the system identification method have arbitrary values because they are determined such that the relationship between input, $u$, and output, $y$, is simply satisfied. The state variable serves as intermediate variables that connect between the input and output, and there are infinite possible state variables that satisfy the relationship between input and output. Therefore, the corresponding state matrices have no physical meaning. In this study, the state space model realized from the vibration test is denoted as an arbitrary state space model.

The arbitrary state space model obtained from vibration test using the system identification method can be expressed as

$$
\begin{gathered}
\dot{\overline{\mathbf{z}}}=\overline{\mathbf{A}} \overline{\mathbf{z}}+\overline{\mathbf{b}} u, \\
y=\overline{\mathbf{c z}}+\overline{\mathbf{d}} u,
\end{gathered}
$$

where $\overline{\mathbf{z}}$ is the state variable and $\overline{\mathbf{A}}, \overline{\mathbf{b}}, \overline{\mathbf{c}}$, and $\overline{\mathbf{d}}$ are system matrices realized by the system identification.

As described above, the state variable, $\mathbf{z}$, in (10a) and (10b) has physical meaning of modal displacement and velocity in modal coordinate, but the state variable, $\overline{\mathbf{z}}$, in (11a) and (11b) has no physical meaning. Therefore, the system matrix $\overline{\mathbf{b}}$ realized by the system identification is generally different from the system matrix $\mathbf{b}$ of the typical state space model. In order to estimate the modal participation factor from the vibration test, consequently, it is required to obtain the system matrices of the typical state space model from those of the arbitrary state space model. That is, it is required to find a relationship between the state variables, $\mathbf{z}$, of the typical state space model and $\overline{\mathbf{z}}$ of the arbitrary state space model.

If the transformation matrix $\mathbf{T}$ transforms the state variable, $\overline{\mathbf{z}}$, in (11a) and (11b) into the state variable, $\mathbf{z}$, in (10a) and (10b), the relationship is given by

$$
\mathbf{z}=\mathbf{T} \overline{\mathbf{z}}
$$

Substituting (12) into (10a) and (10b) leads to

$$
\begin{gathered}
\dot{\overline{\mathbf{z}}}=\mathbf{T}^{-1} \mathbf{A T} \overline{\mathbf{z}}+\mathbf{T}^{-1} \mathbf{b} u, \\
y=\mathbf{c} \mathbf{T} \overline{\mathbf{z}}+\mathbf{d} u .
\end{gathered}
$$

Comparing (13a) and (13b) and (11a) and (11b), the following relationships between the system matrices of two state space models are obtained

$$
\mathbf{Q T}=\overline{\mathbf{Q}},
$$

where $\mathbf{Q}$ and $\overline{\mathbf{Q}}$ are the observability matrices of the typical and arbitrary state space models, respectively [21, 22]. The observability matrix is a measure whether the information 
on the state variable can be determined from the output of a system and is defined by

$$
\mathbf{Q}=\left(\begin{array}{c}
\mathbf{c} \\
\mathbf{c A} \\
\mathbf{c A}^{2} \\
\vdots \\
\mathbf{c A}^{2 n-1}
\end{array}\right) \text {. }
$$

The transformation matrix in (12) is obtained from (14) as

$$
\mathbf{T}=\mathbf{Q}^{-1} \overline{\mathbf{Q}}
$$

and the relationship between the system matrix $\overline{\mathbf{b}}$ realized by the system identification and the system matrix $\mathbf{b}$ of the typical state space model is given by

$$
\mathbf{Q b}=\overline{\mathbf{Q b}} \text {. }
$$

Referring to (8a) and (8b), the values of first $n$ rows of vector $\mathbf{b}$ are all zeros. Therefore, the observability matrix of the typical state space model in (17) can be rewritten in partitioned form as

$$
\left(\begin{array}{ll}
\mathbf{Q}_{11} & \mathbf{Q}_{12} \\
\mathbf{Q}_{21} & \mathbf{Q}_{22}
\end{array}\right)\left(\begin{array}{c}
\mathbf{O}_{n \times 1} \\
-\{\Gamma\}_{p}
\end{array}\right)=\left(\begin{array}{c}
\overline{\mathbf{Q}}_{1} \\
\overline{\mathbf{Q}}_{2}
\end{array}\right) \overline{\mathbf{b}}
$$

where $\mathbf{Q}_{11}, \mathbf{Q}_{12}, \mathbf{Q}_{21}$, and $\mathbf{Q}_{22}$ are $n \times n$ submatrices of $\mathbf{Q}$ and $\overline{\mathbf{Q}}_{1}$ and $\overline{\mathbf{Q}}_{2}$ are $n \times 1$ submatrices of $\overline{\mathbf{Q}}$. Finally from (18), the modal participation factors of modes normalized to $p$ th element are given by

$$
\{\Gamma\}_{p}=-\mathbf{Q}_{22}^{-1} \overline{\mathbf{Q}}_{2} \overline{\mathbf{b}}
$$

It is noted that $\mathbf{Q}_{22}$ and $\overline{\mathbf{Q}}_{2}$ are only used to calculate the modal participation factor in (19). This is to avoid mathematical ill-conditioning during the inverse matrix calculation.

2.3. Mode Shape Estimation from Modal Participation Factors. The mode shape can be estimated directly from the experimentally estimated modal participation factors based on the simple relationship between factors. From (5), the modal participation factor of $i$ th mode, $\left\{\Gamma_{i}\right\}_{j}$, obtained using the $i$ th mode shape normalized to $j$ th element is given by

$$
\left\{\Gamma_{i}\right\}_{j}=\frac{\left(\phi_{i}\right)_{j}^{T} \mathbf{M}\{1\}}{\left(\phi_{i}\right)_{j}^{T} \mathbf{M}\left(\phi_{i}\right)_{j}},
$$

where $\left(\phi_{i}\right)_{j}$ is the $i$ th mode shape normalized to the $j$ th element. If $\left(\phi_{i}\right)_{k}$ is the $i$ th mode shape normalized to the $k$ th element, the $\left(\phi_{i}\right)_{k}$ is related to $\left(\phi_{i}\right)_{j}$ by

$$
\left(\phi_{i}\right)_{k}=\frac{\left(\phi_{i}\right)_{j}}{\left(\phi_{k i}\right)_{j}}
$$

where $\left(\phi_{k i}\right)_{j}$ is the $k$ th element of the $i$ th mode shape normalized to the $j$ th element. Substituting (21) into (20) leads to

$$
\left\{\Gamma_{i}\right\}_{j}=\frac{1}{\left(\phi_{k i}\right)_{j}} \frac{\left(\phi_{i}\right)_{k}^{T} \mathbf{M}\{1\}}{\left(\phi_{i}\right)_{k}^{T} \mathbf{M}\left(\phi_{i}\right)_{k}}=\frac{1}{\left(\phi_{k i}\right)_{j}}\left\{\Gamma_{i}\right\}_{k}
$$

where $\left\{\Gamma_{i}\right\}_{k}$ is the modal participation factor of the $i$ th mode obtained using the $i$ th mode shape normalized to $k$ th element.

Accordingly, $k$ th element of the $i$ th mode shape normalized to the $j$ th element can be estimated using the identified modal participation factor as

$$
\left(\phi_{k i}\right)_{j}=\frac{\left\{\Gamma_{i}\right\}_{k}}{\left\{\Gamma_{i}\right\}_{j}}
$$

\section{Numerical Verification}

In this chapter, the proposed procedure is verified numerically using two examples: (1) a 3-story building subjected to the white noise ground acceleration and (2) an 8-story building subjected to the $1940 \mathrm{El}$ Centro earthquake ground acceleration. The following step-by-step procedure is used to estimate the modal participation factors and mode shapes.

Step 1. Identify the arbitrary state space model for the SISO system using any system identification technique.

Step 2. Obtain the modal frequencies and damping ratios from the identified arbitrary state space model.

Step 3. Construct the system matrices $\mathbf{A}$ and $\mathbf{c}$ of the typical state space model using the modal frequencies and damping ratios obtained from Step 2.

Step 4. Calculate the observability matrices of the typical and arbitrary state space models using (15).

Step 5. Calculate the modal participation factor from (19) using the partitioned observability matrices and the system matrix b of the arbitrary state space model identified in Step 1.

Step 6. If more than one floor is measured, the mode shape can be calculated from (23) using the calculated modal participation factors in Step 5.

\subsection{3-Story Building}

3.1.1. Building Description. A 3-story shear building structure is first used for numerical simulation. The mass, damping, and stiffness of each floor are $22.758 \mathrm{~kg}, 6.50 \mathrm{~N} \cdot \mathrm{s} / \mathrm{m}$, and $3,764 \mathrm{~N} / \mathrm{m}$, respectively. These values correspond to the experimental setup used in a laboratory. The natural frequencies are $0.900 \mathrm{~Hz}, 2.522 \mathrm{~Hz}$, and $3.644 \mathrm{~Hz}$ and modal damping ratios are $0.50 \%, 1.40 \%$, and $2.03 \%$. The modal characteristics of the structure are summarized in Tables 1 and 2 . The mode 
TABLE 1: Mode shapes of example structure.

\begin{tabular}{lccc}
\hline Floor & 1st mode & 2nd mode & 3rd mode \\
\hline 1st & 0.445 & -1.247 & 1.802 \\
2nd & 0.802 & -0.555 & -2.247 \\
3rd & 1.000 & 1.000 & 1.000 \\
\hline
\end{tabular}

TABLE 2: Modal participation factors of example structure.

\begin{tabular}{lccc}
\hline Normalization floor & 1st mode & 2nd mode & 3rd mode \\
\hline 1st floor & 0.543 & 0.349 & 0.108 \\
2nd floor & 0.979 & 0.155 & -0.134 \\
3rd floor & 1.220 & -0.280 & 0.060 \\
\hline
\end{tabular}

shapes are normalized to the third floor in Table 1, and the modal participation factor of each mode is obtained for three cases with different normalization floor in Table 2. As noted in (5), it is apparent that the modal participation factor varies depending on the normalization method of mode shapes.

For the numerical simulation, the white noise is used as ground acceleration and the absolute acceleration of each floor is calculated. The duration of ground motion is 100 seconds with sampling rate of 1/100 second. Figure 1 shows the ground acceleration and numerically calculated absolute acceleration of each floor.

3.1.2. System Identification Results. The system identification using ground acceleration and floor absolute accelerations is performed. Because there are three floor accelerations that can be used as an output of the SISO system, the system identification is performed three times. In the first case, the ground acceleration is used as an input to the SISO system and the first floor acceleration is used as an output. In the second and third cases, the second and third floor accelerations are used as an output to the SISO system, respectively, as summarized in Table 3. The system identification is performed using N4SID (State Space Subspace System Identification) method [15]. The state space model is used for the identification and the order of state space model is 6 .

The system matrices of the arbitrary state space model obtained from the system identification using ground acceleration and the first floor acceleration (Case 1) are summarized in Table 4. In Figure 2, the transfer function for the first floor absolute acceleration from ground acceleration calculated using system matrices in Table 3 is compared to that of the analytical model. It can be noticed from Figure 2 that the identified transfer function matches well that of analytical model.

3.1.3. Results of Modal Participation Factor Estimation. The modal frequencies and damping ratios obtained from system matrices presented in Table 4 are summarized in Table 5. Using the modal frequencies and damping ratios presented in Table 5, the system matrices $\mathbf{A}$ and $\mathbf{c}$ are calculated from (8a), (8b), (10a), and (10b) as given in Table 6.
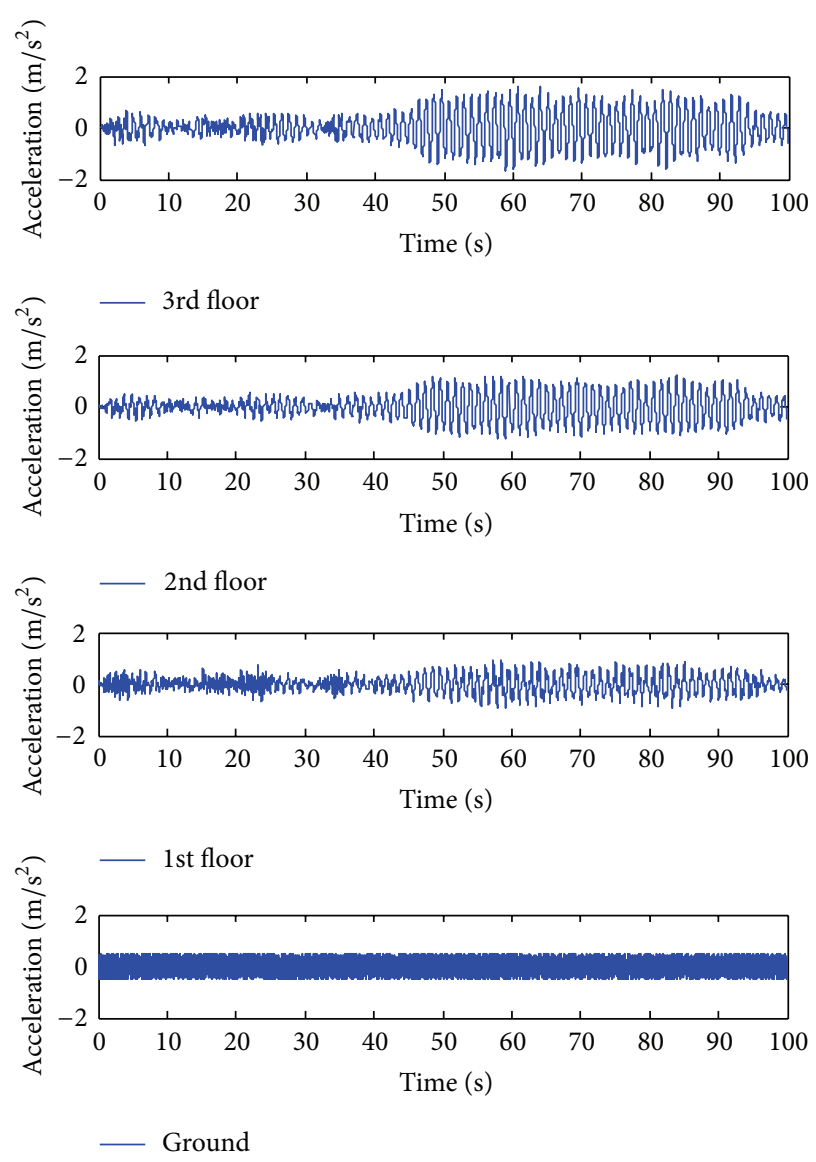

FIGURE 1: Ground and numerically calculated floor acceleration time histories of 3-story building.

TABLE 3: Input and output signals for system identification.

\begin{tabular}{llc}
\hline Identification number & Input & Output \\
\hline Case 1 & Ground acc. & 1st floor acc. \\
Case 2 & Ground acc. & 2nd floor acc. \\
Case 3 & Ground acc. & 3rd floor acc. \\
\hline
\end{tabular}

TABLE 4: Identification result for Case 1.

\begin{tabular}{ccccccc}
\hline & -0.419 & -13.065 & -6.055 & 0.116 & 6.495 & 0.912 \\
& 13.518 & -0.117 & 6.929 & -3.925 & -1.708 & 5.179 \\
$\overline{\mathbf{A}}$ & 6.102 & -6.950 & 0.006 & -6.676 & -11.496 & -6.165 \\
& 0.112 & 3.821 & 6.675 & -0.011 & -11.120 & 1.737 \\
& -5.325 & 1.080 & 11.420 & 10.806 & -0.814 & -11.596 \\
& -0.548 & -5.383 & 6.149 & -1.845 & 11.078 & -0.073 \\
\hline$\overline{\mathbf{b}}^{T}$ & 0.290 & -0.171 & 0.015 & -0.105 & -0.495 & -0.120 \\
\hline$\overline{\mathbf{c}}$ & 21.014 & 11.004 & 5.744 & -1.878 & 14.048 & -22.794 \\
\hline$\overline{\mathbf{d}}$ & 0 & & & & & \\
\hline
\end{tabular}

The observability matrices of the typical and arbitrary state space models are calculated as in (24) and (25), respectively, using (15) and the system matrices presented in Tables 4 


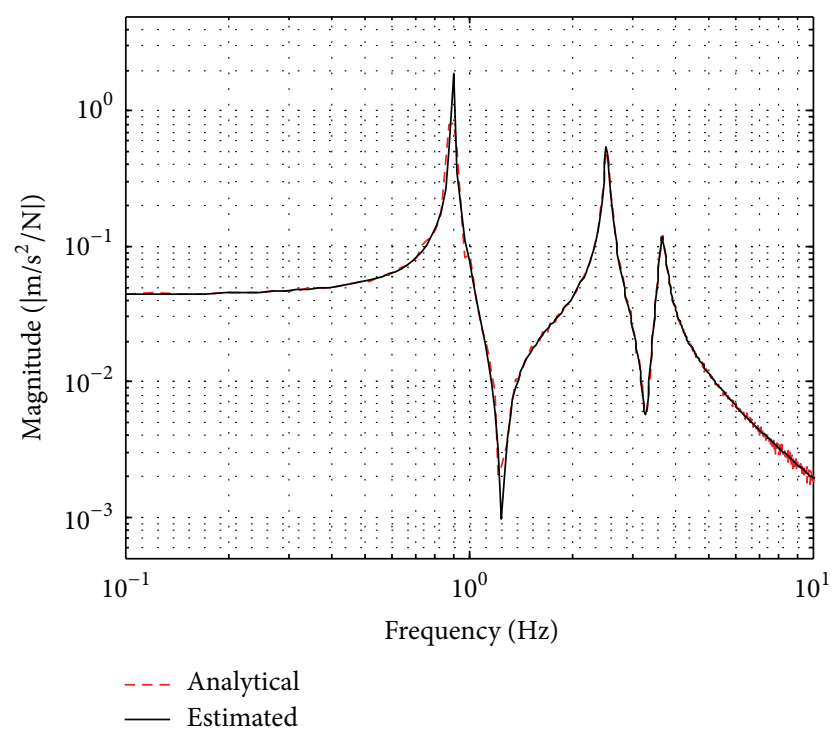

FIGURE 2: Comparison of the magnitude of frequency response functions (accelerances) for the first floor acceleration.

and 6. For the sake of brevity, the partitioned observability matrices used in (18) are presented:

$$
\begin{gathered}
\mathbf{Q}_{22}=10^{8} \times\left(\begin{array}{ccc}
0 & 0.001 & 0.003 \\
0 & -0.001 & -0.008 \\
0 & -0.157 & -1.426
\end{array}\right) \\
\overline{\mathbf{Q}}_{2}^{T}=10^{7} \times\left(\begin{array}{ccc}
-0.002 & 0.016 & 1.317 \\
0.004 & 0.024 & -0.731 \\
0 & 0.147 & -0.118 \\
0.002 & 0.049 & -1.094 \\
0.007 & -0.013 & -2.832 \\
0.003 & -0.061 & -0.530
\end{array}\right) .
\end{gathered}
$$

Using the above observability matrices and the system matrix $\overline{\mathbf{b}}$ in Table 4 , the modal participation factor is obtained from (19) for the case that mode shapes are normalized to the first floor

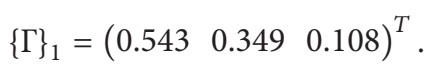

Comparing the modal participation factor given in (26) and that of the analytical model presented in Table 2 for the case of the first floor normalization, it can be concluded that the proposed method estimates the modal participation factor accurately.

The modal participation factor based on the entire system identification results is presented in Table 7. Again, it is evident that the proposed method estimates the modal participation factor correctly compared to that given in Table 2 .

3.1.4. Mode Shape Estimation. In Table 8, the estimated mode shapes that are calculated using (23) and the modal participation factors given in Table 7 are presented. Figure 3 shows
TABLE 5: Identified modal frequencies and damping ratios for Case 1.

\begin{tabular}{lcc}
\hline Mode & Modal frequency $(\mathrm{Hz})$ & Modal damping ratio (\%) \\
\hline 1st mode & 0.900 & 0.50 \\
2nd mode & 2.522 & 1.40 \\
3rd mode & 3.644 & 2.03 \\
\hline
\end{tabular}

TABLE 6: System matrices A and $\mathbf{c}$ of the typical state space model for Case 1.

\begin{tabular}{ccccccc}
\hline & 0 & 0 & 0 & 1 & 0 & 0 \\
& 0 & 0 & 0 & 0 & 1 & 0 \\
& 0 & 0 & 0 & 0 & 0 & 1 \\
& -31.974 & 0 & 0 & -0.057 & 0 & 0 \\
& 0 & -251.029 & 0 & 0 & -0.444 & 0 \\
& 0 & 0 & -524.185 & 0 & 0 & -0.927 \\
\hline c & -31.975 & -251.029 & -524.185 & -0.057 & -0.444 & -0.927 \\
\hline
\end{tabular}

TABLE 7: Results of modal participation factor estimation.

\begin{tabular}{lccc}
\hline & 1st mode & 2nd mode & 3rd mode \\
\hline Case 1 & 0.543 & 0.349 & 0.108 \\
Case 2 & 0.979 & 0.155 & -0.134 \\
Case 3 & 1.220 & -0.280 & 0.060 \\
\hline
\end{tabular}

TABLE 8: Results of mode shape estimation.

\begin{tabular}{lccc}
\hline Floor & 1st mode & 2nd mode & 3rd mode \\
\hline 1st floor & 0.450 & -1.248 & 1.792 \\
2nd floor & 0.808 & -0.557 & -2.230 \\
3rd floor & 1.000 & 1.000 & 1.000 \\
\hline
\end{tabular}

the comparison of the estimated mode shapes to those of analytical model given in Table 1 . The mode shapes obtained using the common based-normalized system identification (CBSI) method proposed by Alvin and Park [23] are also presented in Figure 3. The mode shapes of the analytical model are denoted as "Analytical," those estimated by the proposed method are denoted as "P-factor," and those obtained by the CBSI method is denoted as "CBSI." It is observed from Figure 3 that the proposed mode shape estimation method based on modal participation factor identification provides accurate results.

\subsection{8-Story Building}

3.2.1. Building Description. An 8-story shear building structure is used for the second numerical simulation. The mass, damping, and stiffness of each floor are $416.84 \mathrm{~kg}$, $454.55 \mathrm{~N} \cdot \mathrm{s} / \mathrm{m}$, and $100 \mathrm{kN} / \mathrm{m}$, respectively. The first three natural frequencies are $0.455 \mathrm{~Hz}, 1.349 \mathrm{~Hz}$, and $2.198 \mathrm{~Hz}$ and modal damping ratios are $0.65 \%, 1.93 \%$, and $3.14 \%$. For the numerical simulation, the 1940 El Centro earthquake record is used as ground acceleration and the absolute acceleration of each floor is calculated. The duration of ground motion is 60 seconds with sampling rate of 0.02 second. Figure 4 shows 


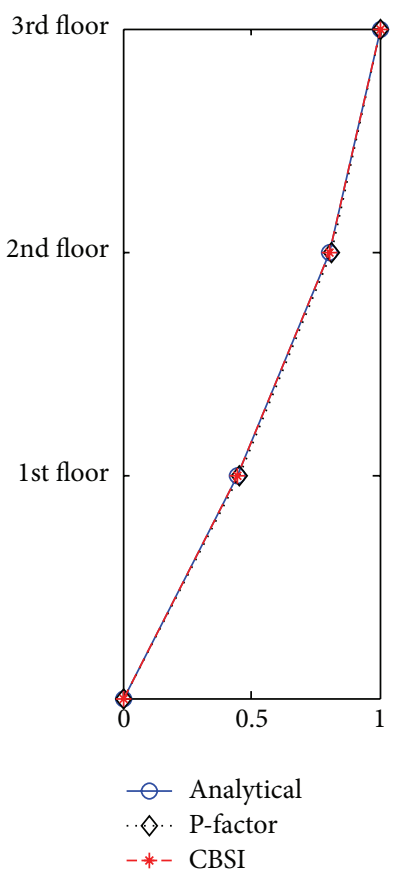

(a) 1st mode

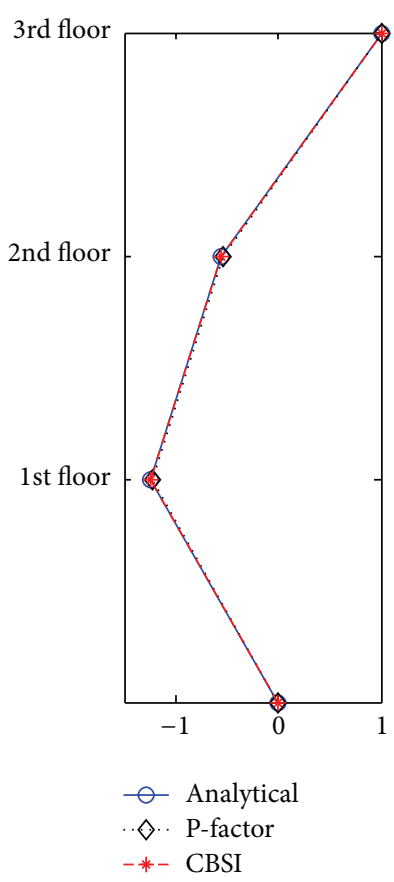

(b) 2nd mode

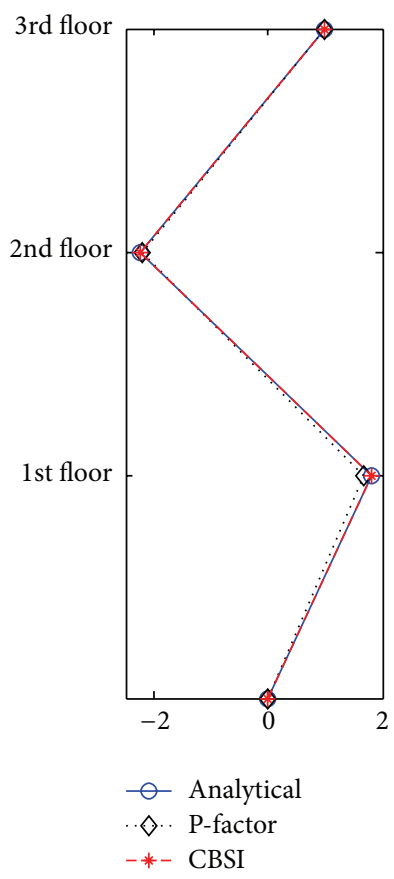

(c) 3rd mode

Figure 3: Mode shape comparison.
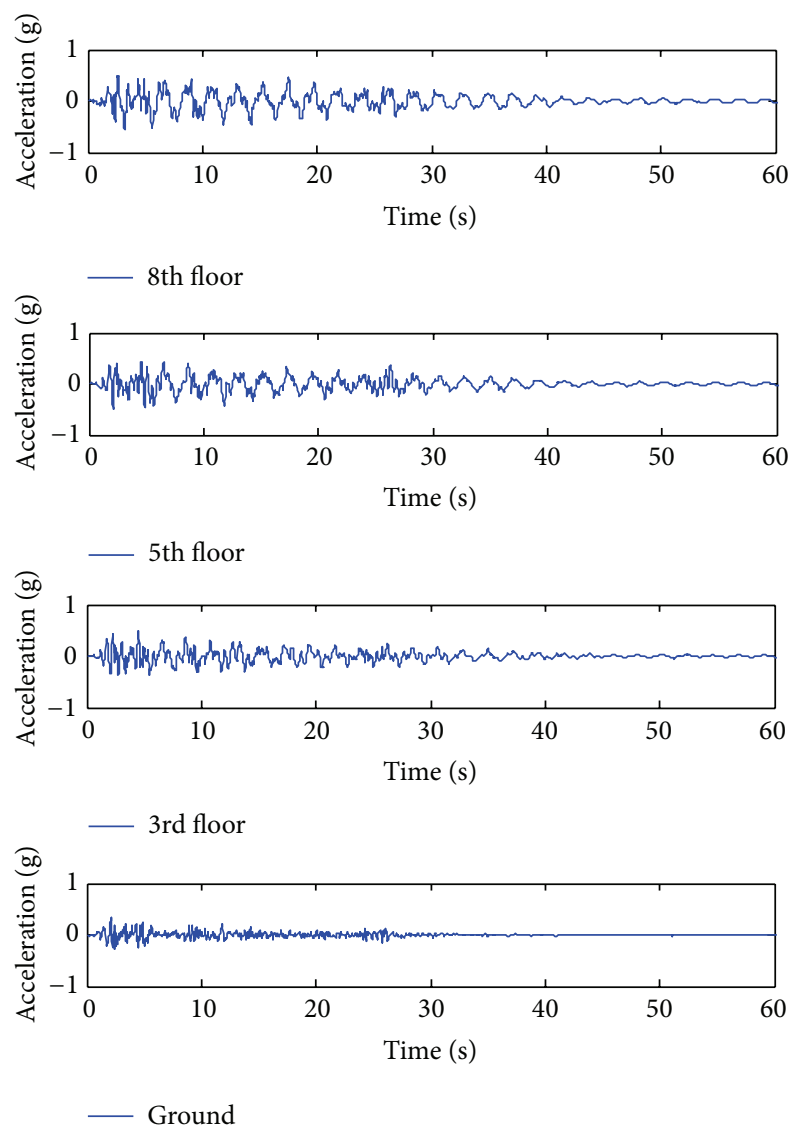

FIGURE 4: Ground and numerically calculated floor acceleration time histories of 8-story building. the ground acceleration and numerically calculated absolute acceleration of selected floors.

3.2.2. System Identification Results and Mode Shape Estimation. Similar to the 3-story building example, the system identification using ground acceleration and floor absolute accelerations is performed eight times. In Figure 5, the transfer functions for the fourth and eighth floor absolute acceleration from ground acceleration are compared to that of the analytical model. It can be noticed from Figure 5 that the identified transfer function matches well that of analytical model.

The estimated mode shapes using the proposed method are compared to those of analytical model in Figure 6. As in the 3 -story building example, it can be seen from Figure 6 that the proposed mode shape estimation method based on modal participation factor identification provides accurate results.

\section{Experimental Verification}

4.1. Test Setup. For the experimental verification of the proposed method, the shaking table test is performed. Figure 7 shows the schematic and photograph of the shaking table test. The shaking table used in the experiment is a uniaxial servo-hydraulic shaking table with a horizontal force capacity of $2.0 \mathrm{KN}$. The story height of the test building is $600 \mathrm{~mm}$ and columns with width of $50 \mathrm{~mm}$ and thickness of $2 \mathrm{~mm}$ are installed such that the building behaves in the weak axis direction. Each floor consists of $650 \mathrm{~mm} \times 650 \mathrm{~mm} \times 4 \mathrm{~mm}$ steel plate and is stiffened with circumferential steel plate of 


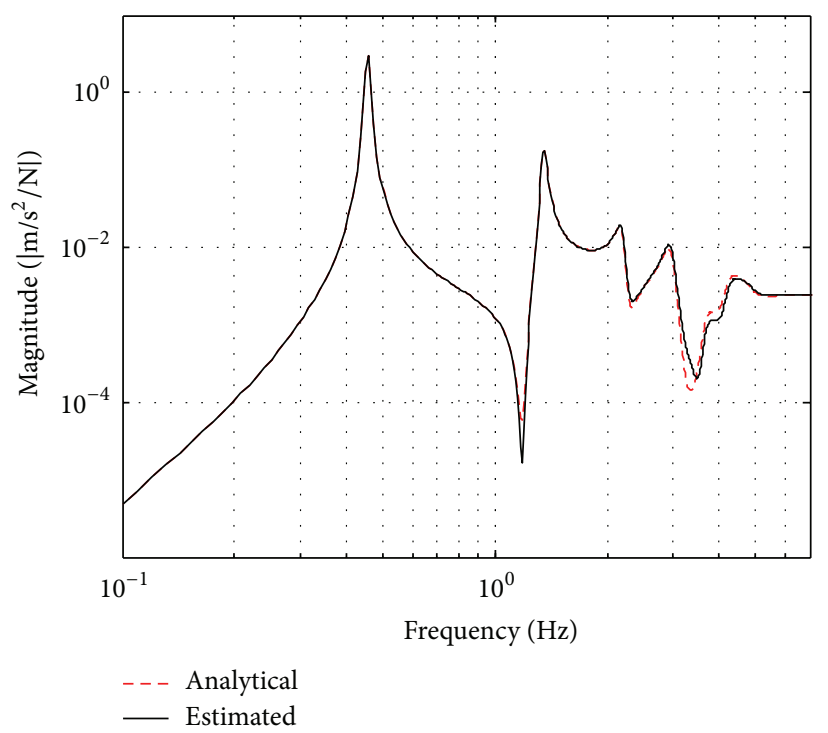

(a) Fourth floor

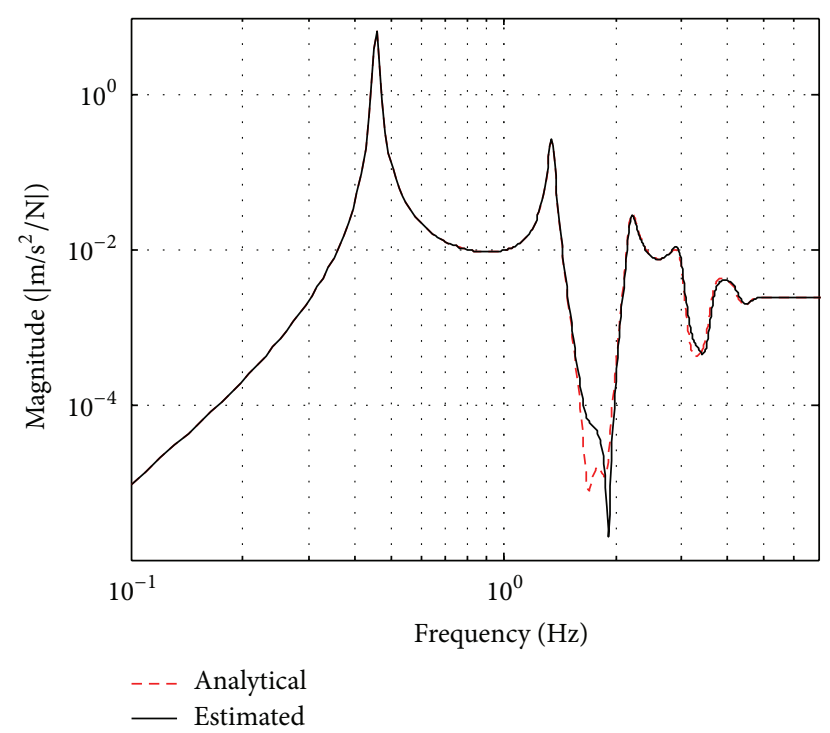

(b) Eighth floor

FIGURE 5: Comparison of the magnitude of frequency response functions (accelerances) for the fourth and eighth floor accelerations.

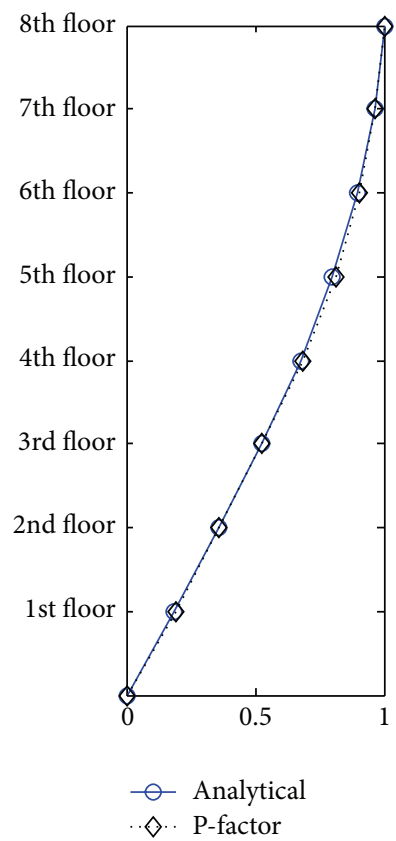

(a) 1st mode

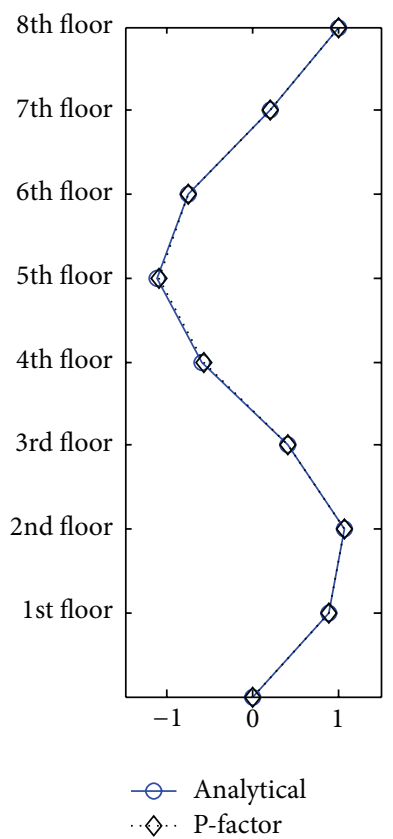

(b) 3rd mode

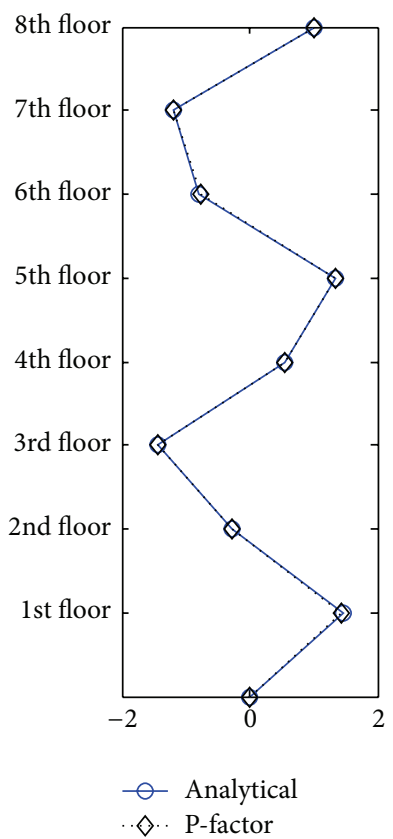

(c) 5th mode

FIGURE 6: Mode shape comparison.

$50 \mathrm{~mm} \times 4 \mathrm{~mm}$. The story mass including accelerometer is $22.785 \mathrm{~kg}$.

Four wireless MEMS systems with the ADXL103 sensor [24] are installed in each floor to measure the floor acceleration as well as ground acceleration. The building is excited by the white noise ground motion acting in the weak axis direction, and floor accelerations are measured for 200 seconds with sampling rate of 1/1000 second. The acceleration time histories for the first 100 seconds are presented in Figure 8.
4.2. System Identification and Modal Participation Factor Estimation. Similar to the numerical verification, the system identification is performed using the ground acceleration and the floor acceleration of each floor three times. In Table 9, the system matrices of the arbitrary state space model realized from the system identification using the ground and first floor accelerations (Case 1) are presented. The transfer function for the first floor absolute acceleration from ground acceleration calculated using system matrices in Table 9 is compared to 


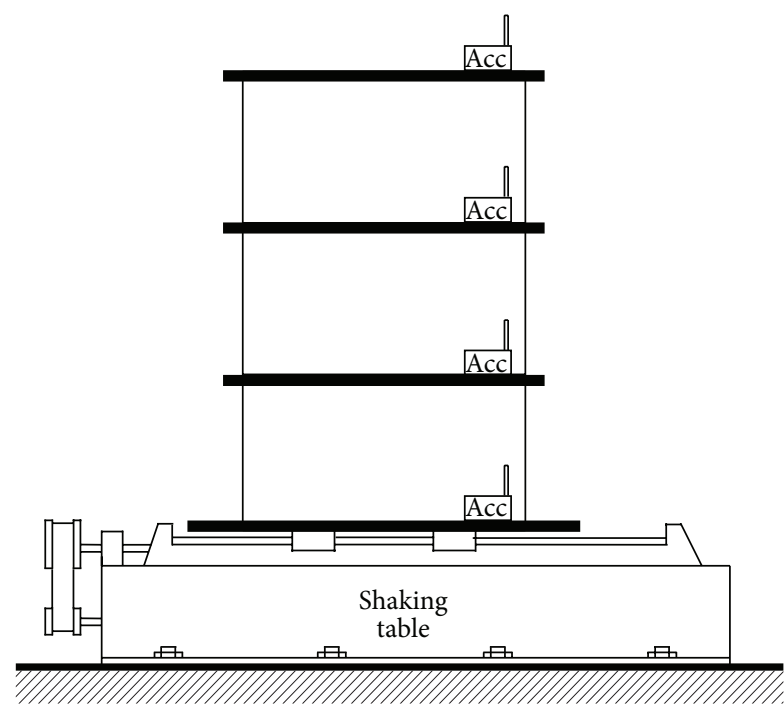

(a) Schematic

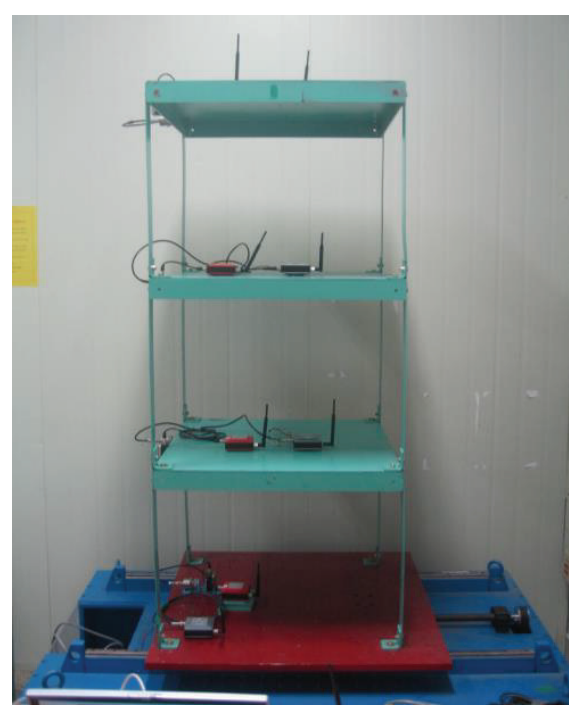

(b) Shaking table test

FIGURE 7: Shaking table test of a three-story building.

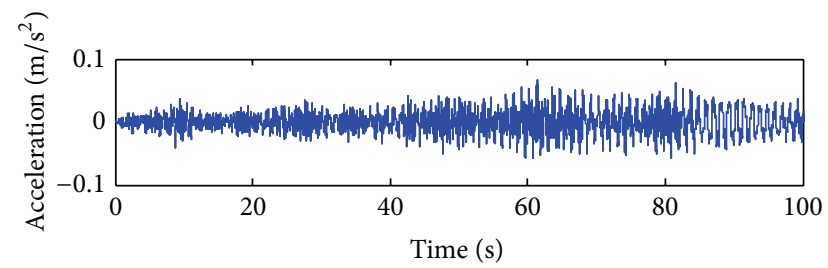

TABLE 9: Identification result for Case 1.

\begin{tabular}{ccccccc}
\hline & -0.009 & 1.782 & -0.167 & 11.901 & -5.116 & 0.624 \\
& -1.133 & 0.017 & 9.433 & 0.047 & 0.006 & -1.273 \\
$\overline{\mathbf{A}}$ & 0.072 & -9.179 & 0.033 & 14.317 & -2.164 & 0.550 \\
& -6.598 & -0.166 & -12.100 & -0.092 & 0.314 & -11.406 \\
& 0.550 & -0.024 & 0.383 & -0.242 & 0.151 & 29.586 \\
& 0.084 & -0.044 & 0.046 & 0.969 & -19.618 & -1.002 \\
\hline$\overline{\mathbf{b}}^{T}$ & -1.757 & -0.263 & -0.904 & -2.484 & -0.461 & -0.290 \\
\hline$\overline{\mathbf{c}}$ & 1.847 & -0.284 & 0.761 & -1.881 & 1.447 & -3.827 \\
\hline$\overline{\mathbf{d}}$ & 0 & & & & & \\
\hline
\end{tabular}

TABLE 10: Estimation results of dynamic characteristics for Case 1.

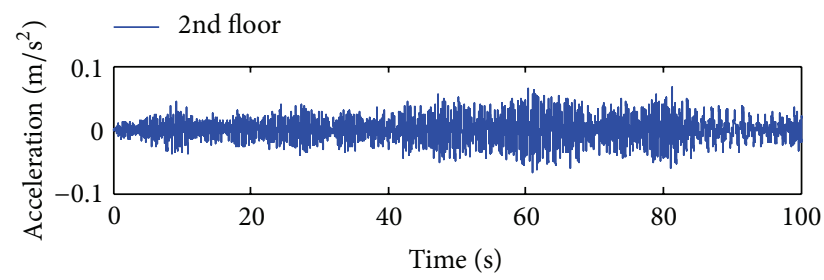

\begin{tabular}{lccc}
\hline Mode & $\begin{array}{c}\text { Modal } \\
\text { frequency (Hz) }\end{array}$ & $\begin{array}{c}\text { Modal damping } \\
\text { ratio (\%) }\end{array}$ & $\begin{array}{c}\text { Modal } \\
\text { participation } \\
\text { factor }\end{array}$ \\
\hline 1st mode & 0.903 & 0.92 & 0.694 \\
2nd mode & 2.684 & 0.89 & 0.357 \\
3rd mode & 3.958 & 1.00 & 0.061 \\
\hline
\end{tabular}

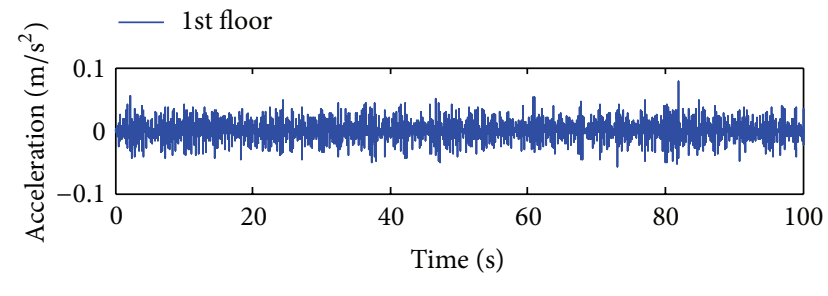

accelerations and the solid line is the one calculated using system matrices given in Table 9.

Figure 10 shows the correlogram between the measured first floor acceleration and the analytically estimated one using the system matrices given in Table 9. The corresponding correlation coefficient is 0.965 indicating that the realized system from system identification is reliable.

FIGURE 8: Measured floor accelerations.

that of the analytical model in Figure 9. The dotted line in

The modal frequencies, damping ratios obtained using the system matrices given in Table 9, and the corresponding modal participation factor calculated from (19) are presented in Table 10. The modal participation factor given in Table 10 is the one for mode shapes normalized to the first floor. 


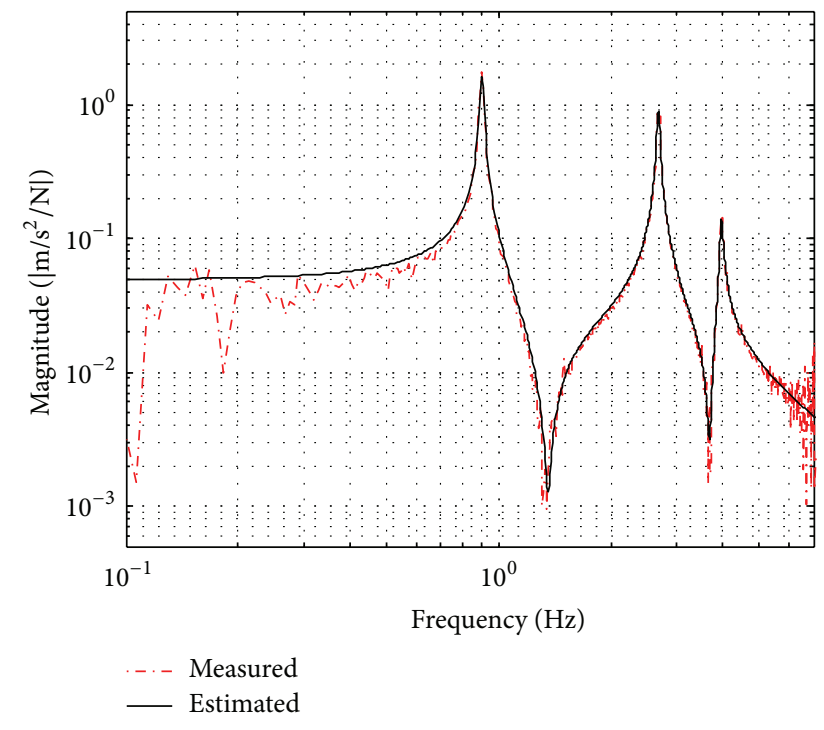

Figure 9: Comparison of the magnitude of frequency response functions (accelerances) for the first floor acceleration.

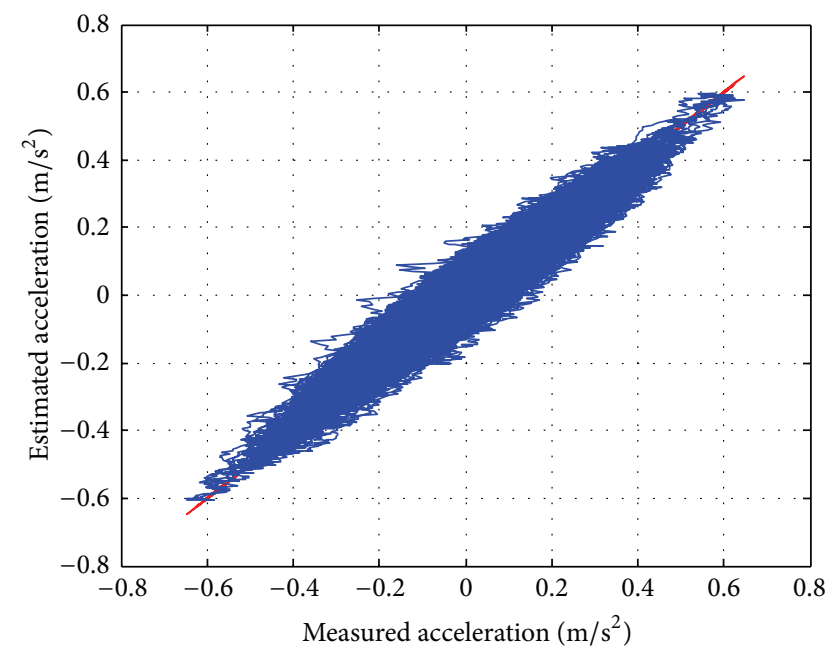

Figure 10: Correlogram between the measured and estimated acceleration for Case 1 (correlation coefficient $=0.965$ ).

The system identification result and the corresponding modal participation factor using the ground and second floor accelerations (Case 2) are presented in Tables 11 and 12 and Figures 11 and 12. The system identification result and the corresponding modal participation factor using the ground and third floor accelerations (Case 3) are presented in Tables 13 and 14 and Figures 13 and 14.

From Figures 12 and 14, it is observed that the system matrices based on the second and third floor accelerations are identified with reliable accuracy similar to those realized using the first floor acceleration. Further, the almost same modal frequencies and damping ratio are identified regardless of system identification cases as seen in Tables 10, 12, and 14.
TABLE 11: Identification result for Case 2.

\begin{tabular}{ccccccc}
\hline & -0.053 & -5.670 & -0.088 & 0.031 & -0.068 & -0.021 \\
& 5.670 & -0.052 & -0.074 & 0.036 & -0.079 & -0.018 \\
$\overline{\mathbf{A}}$ & 0.088 & -0.074 & -0.370 & 23.167 & -5.694 & -0.093 \\
& 0.031 & -0.036 & -23.167 & -0.064 & 0.148 & 0.637 \\
& -0.068 & 0.079 & 5.694 & 0.148 & -0.345 & -18.250 \\
& 0.021 & -0.018 & -0.093 & -0.637 & 18.250 & -0.024 \\
\hline$\overline{\mathbf{b}}^{T}$ & -1.816 & 1.777 & 1.380 & 0.570 & -1.251 & 0.326 \\
\hline$\overline{\mathbf{c}}$ & 1.816 & 1.777 & 1.380 & -0.570 & 1.251 & 0.326 \\
\hline$\overline{\mathbf{d}}$ & 0 & & & & & \\
\hline
\end{tabular}

TABLE 12: Estimation results of dynamic characteristics for Case 2.

\begin{tabular}{lccc}
\hline Mode & $\begin{array}{c}\text { Modal } \\
\text { frequency (Hz) }\end{array}$ & $\begin{array}{c}\text { Modal damping } \\
\text { ratio (\%) }\end{array}$ & $\begin{array}{c}\text { Modal } \\
\text { participation } \\
\text { factor }\end{array}$ \\
\hline 1st mode & 0.903 & 0.93 & 1.138 \\
2nd mode & 2.684 & 0.86 & 0.080 \\
3rd mode & 3.958 & 1.03 & -0.103 \\
\hline
\end{tabular}

TABLE 13: Identification result for Case 3.

\begin{tabular}{ccccccc}
\hline & -0.120 & 6.463 & 1.034 & -0.283 & 0.520 & -2.396 \\
& -5.206 & -0.009 & 0.187 & 4.799 & -6.451 & 0.153 \\
$\overline{\mathbf{A}}$ & -0.247 & 0.098 & 0.004 & 20.120 & -4.698 & 0.525 \\
& 0.122 & -1.176 & -17.659 & -0.219 & 0.279 & -7.925 \\
& -0.147 & 1.214 & 1.557 & -0.123 & -1.027 & 28.118 \\
& -0.312 & -0.241 & -0.104 & 2.056 & -18.151 & 0.456 \\
\hline$\overline{\mathbf{b}}^{T}$ & -4.176 & -1.719 & -0.243 & -1.806 & -0.676 & 0.449 \\
\hline$\overline{\mathbf{c}}$ & 0.395 & -1.645 & -0.765 & 2.339 & -2.252 & 2.648 \\
\hline$\overline{\mathbf{d}}$ & 0 & & & & & \\
\hline
\end{tabular}

TABLE 14: Estimation results of dynamic characteristics for Case 3.

\begin{tabular}{lccc}
\hline Mode & $\begin{array}{c}\text { Modal } \\
\text { frequency }(\mathrm{Hz})\end{array}$ & $\begin{array}{c}\text { Modal damping } \\
\text { ratio (\%) }\end{array}$ & $\begin{array}{c}\text { Modal } \\
\text { participation } \\
\text { factor }\end{array}$ \\
\hline 1st mode & 0.903 & 0.93 & 1.348 \\
2nd mode & 2.684 & 0.89 & -0.260 \\
3rd mode & 3.960 & 1.02 & 0.052 \\
\hline
\end{tabular}

TABLE 15: Results of mode shape estimation.

\begin{tabular}{lccc}
\hline Floor & 1st mode & 2nd mode & 3rd mode \\
\hline 1st floor & 0.515 & -1.375 & 1.178 \\
2nd floor & 0.844 & -0.307 & -1.978 \\
3rd floor & 1.000 & 1.000 & 1.000 \\
\hline
\end{tabular}

4.3. Mode Shape Estimation. In Table 15, the estimated mode shapes obtained using (23) and modal participation factors given in Tables 10, 12, and 14 are presented. Figure 15 shows the estimated mode shapes comparing to those obtained 


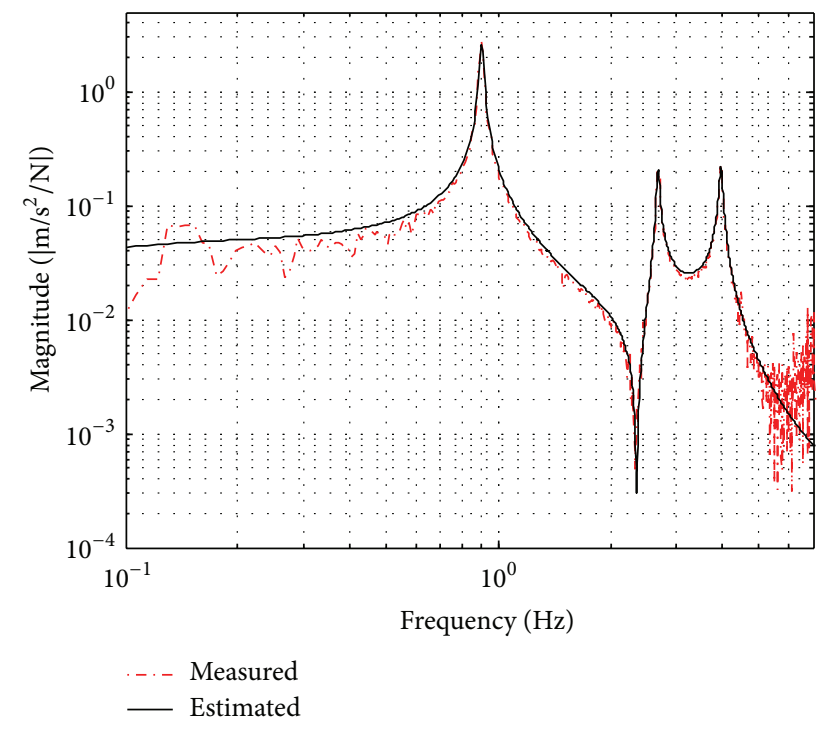

FIGURE 11: Comparison of the magnitude of frequency response functions (accelerances) for the second floor acceleration.

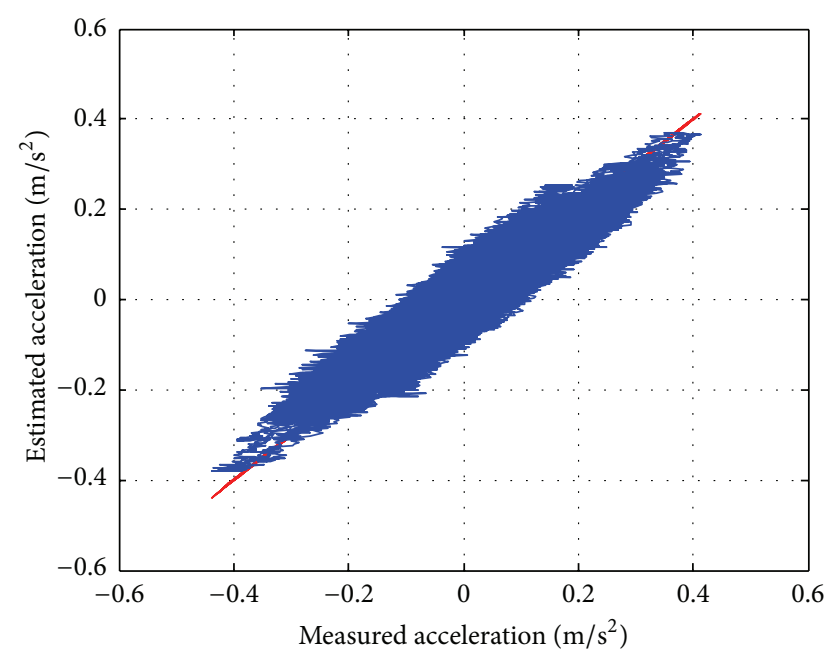

Figure 12: Correlogram between the measured and estimated acceleration for Case 2 (correlation coefficient $=0.948$ ).

using CBSI method. It is observed from Figure 15 that the estimated mode shapes obtained using the proposed method match well those calculated using CBSI method with negligible difference.

\section{Conclusion}

A new method to identify the modal participation factor and mode shape directly from the measured response is presented along with numerical simulations and an experimental verification. The numerical simulation is performed using threeand eight-story shear buildings, and the results show that the modal participation factor and mode shapes are estimated from the structural responses accurately compared to those

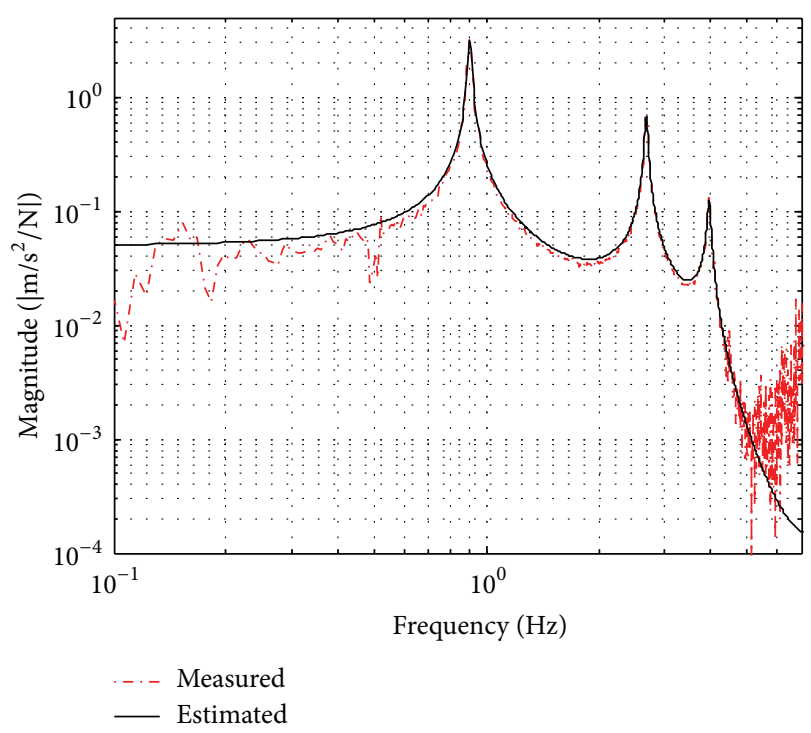

FIGURE 13: Comparison of the magnitude of frequency response functions (accelerances) for the third floor acceleration.

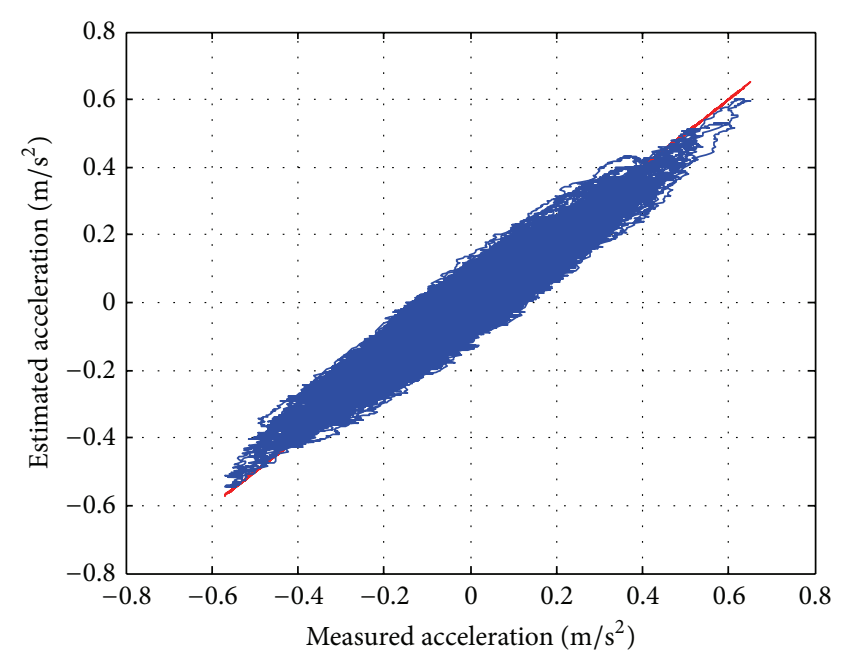

FIGURE 14: Correlogram between the measured and estimated acceleration for Case 3 (correlation coefficient $=0.968$ ).

of the analytical model. The effectiveness of the procedure is evaluated also using the experimental data obtained from the shaking table test of a three-story shear building model. The results indicate that the proposed method yields the modal participation factor and mode shapes with reliable accuracy.

From the numerical simulations and the experimental verification, it can be noted that the modal participation factors can be obtained without knowing the mass and stiffness matrices in advance. Further, it was also shown that the modal participation factor of a certain floor can be estimated without knowing the responses of other floors. This feature makes the proposed method applicable to the vibration test of a large building where the measurement of the dynamic behaviors of every floor is not realistic. 


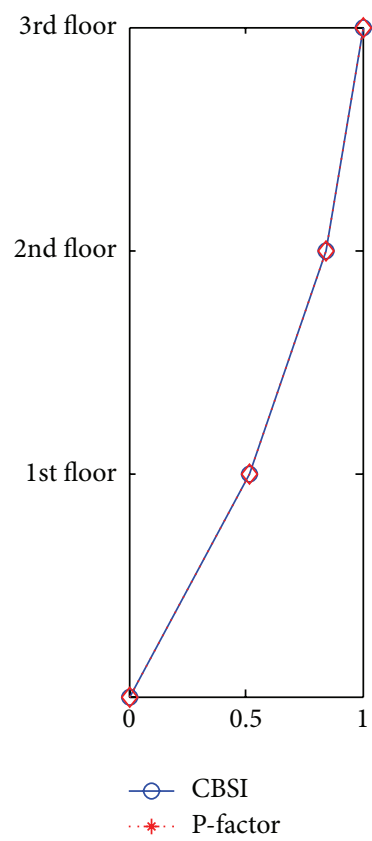

(a) 1st mode

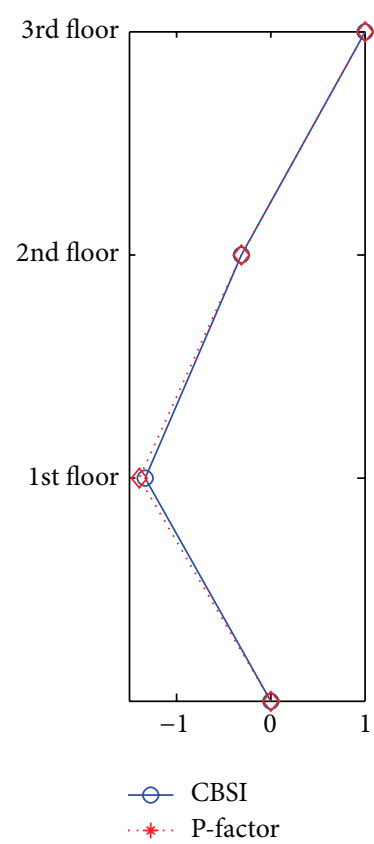

(b) 2nd mode

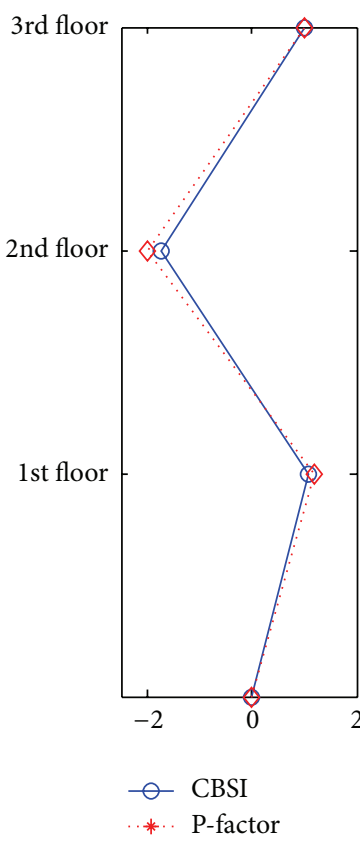

(c) 3rd mode

FIgURE 15: Mode shape comparison.

\section{Conflict of Interests}

The authors declare that there is no conflict of interests regarding the publication of this paper.

\section{Acknowledgments}

This research was supported by Basic Science Research Program through the National Research Foundation of Korea (NRF) funded by the Ministry of Education (NRF-20100023976). This research was also supported by a Grant (10 RTIP B01) from Regional Development Research Program funded by Ministry of Land, Infrastructure and Transport of Korean government.

\section{References}

[1] H. Hao, T. C. Ang, and J. Shen, "Building vibration to trafficinduced ground motion," Building and Environment, vol. 36, no. 3, pp. 321-336, 2001.

[2] B. M. New, "Ground vibration caused by construction works," Tunnelling and Underground Space Technology incorporating Trenchless, vol. 5, no. 3, pp. 179-190, 1990.

[3] C. Wu, H. Hao, Y. Lu, and S. Sun, "Numerical simulation of structural responses on a sand layer to blast induced ground excitations," Computers \& Structures, vol. 82, no. 9-10, pp. 799814,2004

[4] R. W. Clough and P. Penzien, Dynamics of Structure, McGrawHill, New York, NY, USA, 1975.

[5] M. Paz and W. Leigh, Structural Dynamics: Theory and Computation, Kluwer Academic Publishers, Dordrecht, The Netherlands, 5th edition, 2004.
[6] J. Kim and H. Choi, "Displacement-based design of supplemental dampers for seismic retrofit of a framed structure," Journal of Structural Engineering-ASCE, vol. 132, no. 6, pp. 873-883, 2006.

[7] H.-G. Park, T. Eom, and H. Lee, "Factored modal combination for evaluation of earthquake load profiles," Journal of Structural Engineering, vol. 133, no. 7, pp. 956-968, 2007.

[8] E. Reinoso and E. Miranda, "Estimation of floor acceleration demands in high-rise buildings during earthquakes," The Structural Design of Tall and Special Buildings, vol. 14, no. 2, pp. 107130, 2005.

[9] J. M. Bracci, "Simplified seismic evaluation of structures using adaptive pushover analysis," in Computational Methods, Seismic Protection, Hybrid Testing and Resilience in Earthquake Engineering, vol. 33 of Geotechnical, Geological and Earthquake Engineering, pp. 77-96, Springer International Publishing, Cham, Switzerland, 2015.

[10] S.-D. Zhou, L. Liu, W. Yang, and Z.-S. Ma, “Operational modal identification of time-varying structures via a vector multistage recursive approach in hybrid time and frequency domain," Shock and Vibration, vol. 2015, Article ID 397364, 13 pages, 2015.

[11] J.-S. Hwang, H. Kim, and J. Kim, "Estimation of the modal mass of a structure with a tuned-mass damper using $\mathrm{H}$-infinity optimal model reduction," Engineering Structures, vol. 28, no. 1, pp. 34-42, 2006.

[12] H. Kim, W. Kim, B.-Y. Kim, and J.-S. Hwang, "System identification of a building structure using wireless MEMS and PZT sensors," Structural Engineering and Mechanics, vol. 30, no. 2, pp. 191-209, 2008.

[13] T. Liu, A. Li, Y. Ding, and D. Zhao, "Study of the structural damage identification method based on multi-mode information fusion," Structural Engineering and Mechanics, vol. 31, no. 3, pp. 333-347, 2009.

[14] J.-N. Juang, Applied System Identification, Prentice Hall, Englewood Cliffs, NJ, USA, 1994. 
[15] L. Ljung, System Identification Toolbox User's Guide, Mathworks, Natick, Mass, USA, 2007.

[16] J. S. Bendat, Nonlinear System Analysis and Identification from Random Data, John Wiley \& Sons, New York, NY, USA, 1990.

[17] F. J. Doyle III, R. K. Pearson, and B. A. Ogunnaike, Identification and Control Using Volterra Models, Springer, New York, NY, USA, 2002.

[18] S. S. Afshari, H. Nobahari, and S. A. H. Kordkheili, "Experimental parametric identification of a flexible beam using piezoelectric sensors and actuators," Shock and Vibration, vol. 2014, Article ID 718140, 5 pages, 2014.

[19] B.-H. Cho, J.-S. Jo, S.-J. Joo, and H. Kim, "Dynamic parameter identification of secondary mass dampers based on full-scale tests," Computer-Aided Civil and Infrastructure Engineering, vol. 27, no. 3, pp. 218-230, 2012.

[20] N. Kang, H. Kim, S. Choi, S. Jo, J.-S. Hwang, and E. Yu, "Performance evaluation of TMD under typhoon using system identification and inverse wind load estimation," Computer-Aided Civil and Infrastructure Engineering, vol. 27, no. 6, pp. 455-473, 2012.

[21] T. Kailath, Linear Systems, Prentice-Hall, Englewood Cliffs, NJ, USA, 1980.

[22] C.-T. Chen, Linear System Theory and Design, Oxford University Press, New York, NY, USA, 3rd edition, 1999.

[23] K. F. Alvin and K. C. Park, "Second-order structural identification procedure via state-space-based system identification," AIAA Journal, vol. 32, no. 2, pp. 397-406, 1994.

[24] Analog Devices, Data Sheet-ADXL103/ADXL203, 2014. 

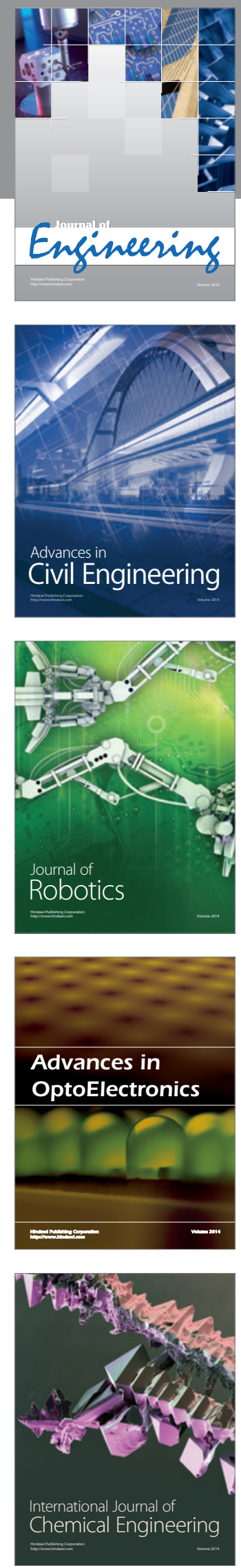

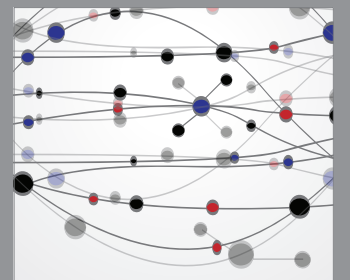

The Scientific World Journal
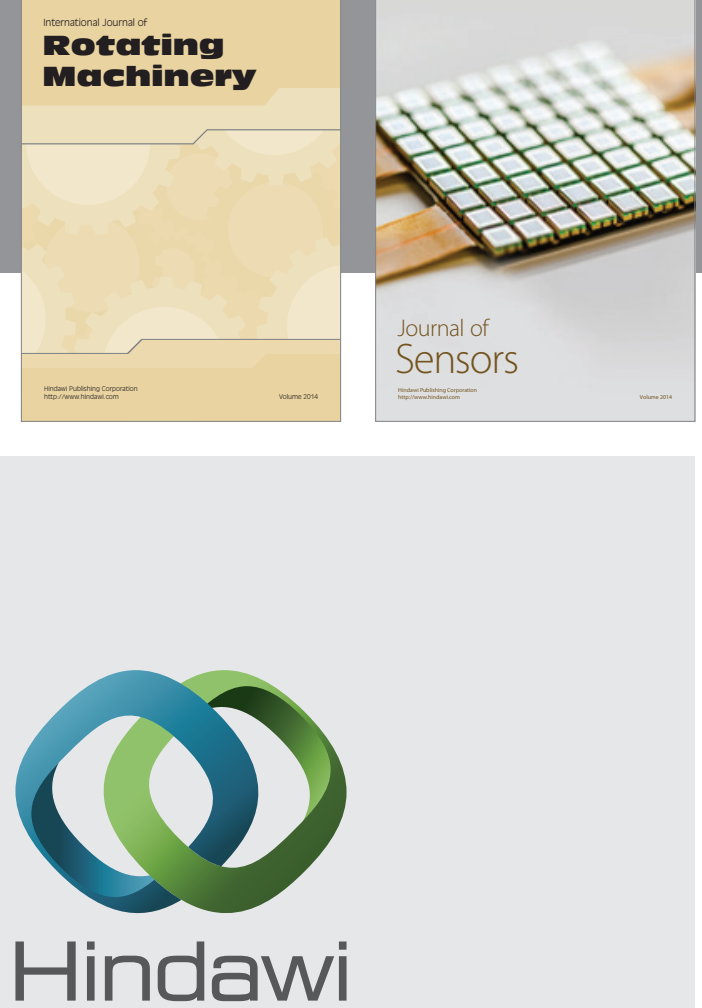

Submit your manuscripts at http://www.hindawi.com
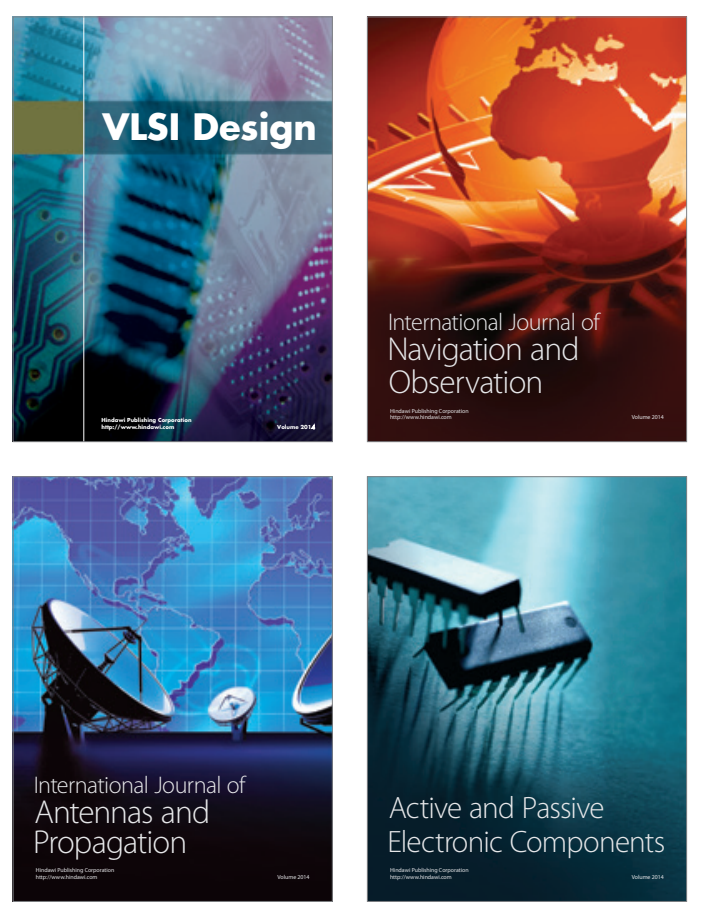
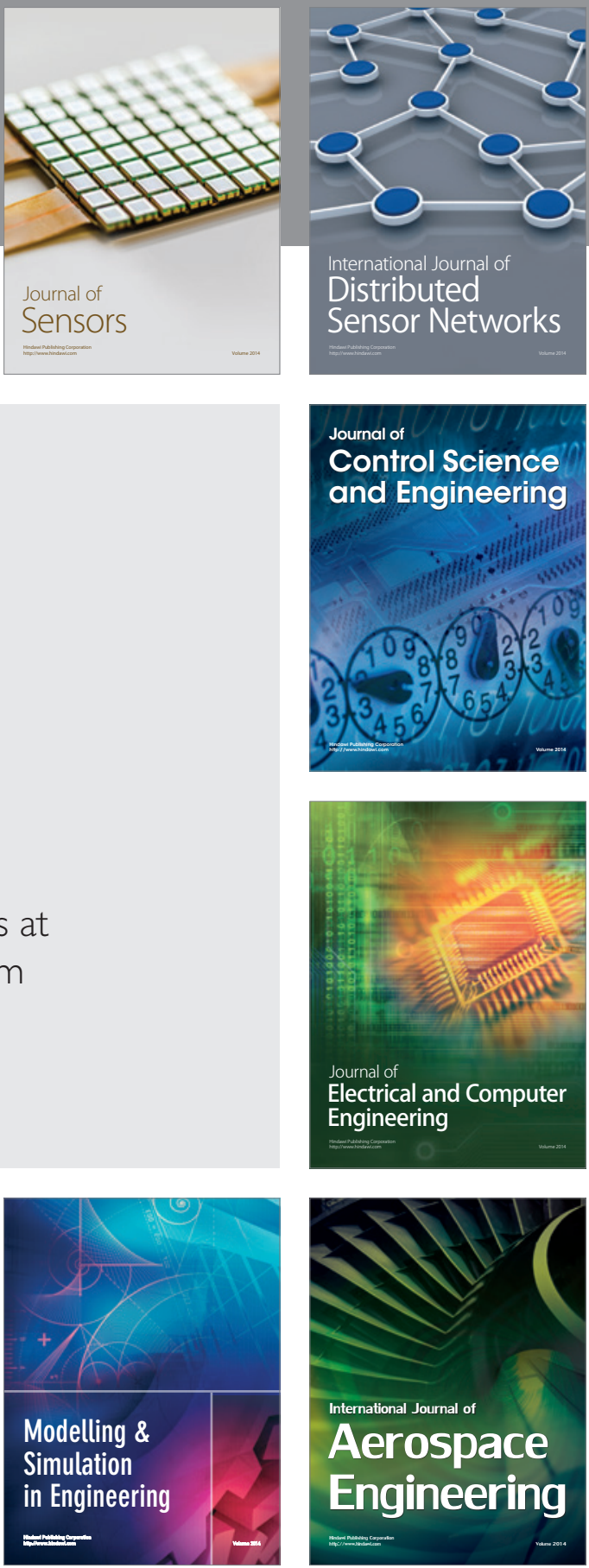

Journal of

Control Science

and Engineering
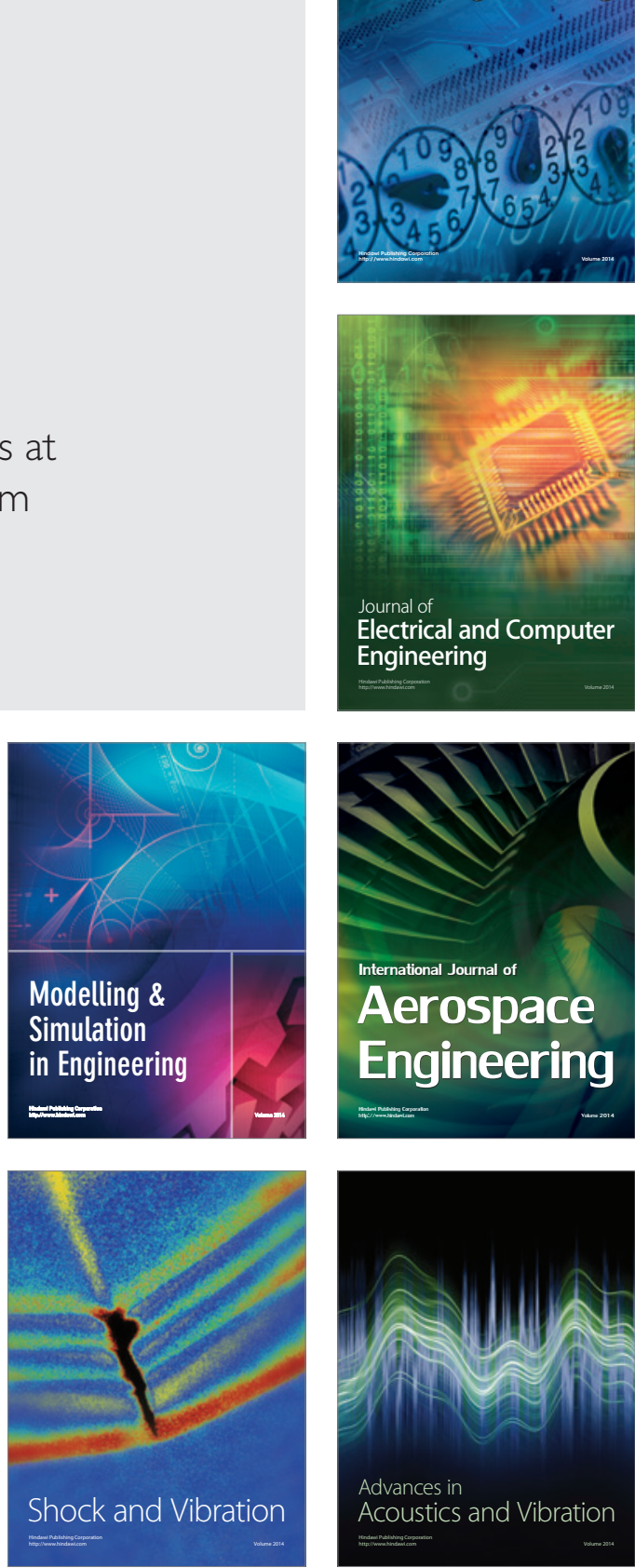